\title{
Toxic effect of nano-zinc oxide
}

\author{
Espanani HR ${ }^{1}$, Faghfoori $\mathrm{Z}^{2}$, Izadpanah $\mathrm{M}^{3}$, Yousefi Babadi $\mathrm{V}^{3}$ \\ Department of Biology, Payame Noor University,Esfahan,Iran- Employee social security organization, \\ Isfahan, Iran. v.yoosefi@gmail.com
}

\begin{abstract}
INTRODUCTION: Nowadays, a lot of studies were carried out about side effects of nanoparticles especially nano-zinc oxide, but unfortunately, most of these studies have been conducted with high doses.

MATERIAL AND METHODS: In the present study 36 male Wistar rats with approximate age of two months and weighing $300 \pm 30 \mathrm{~g}$ were selected. After standard phases of preparation, injections were done intraperitoneally in chronic groups with zinc oxide nanoparticles (20 and $40 \mathrm{mg} / \mathrm{kg}$ ) every other day and for acute groups with 200 and $400 \mathrm{mg} / \mathrm{kg}$ in a single dose. After the determined time for every group (21 days for chronic groups and 7 days for acute groups), blood samples were provided from rat hearts and also liver, kidney and testicular tissue were removed for histological studies.

RESULTS: There were significant decreases in lymphocytes and platelet counts and significant increases in white blood cells count, hemoglobin and hematocrit in acute dose compared to control group and no difference in red blood cells count in all groups. A severe to slight damage was observed in liver tissue in all groups and tissue destruction was seen in kidney only in acute dose treated groups but no specific pathological effect in testis was observed (Fig. 8, Ref. 43). Text in PDF www.elis.sk.

KEY WORDS: nano-zinc oxide, acute and chronic doses, blood parameters, oxidative stress, liver tissue.
\end{abstract}

\section{Introduction}

Zinc oxide $(\mathrm{ZnO})$ is a nonorganic substance and white powder that is widely used as an additive in different materials and productions including plastics, ceramics, glass, cement, tires, lubricants, dyes, sunscreens, glues, pigments, food and batteries, etc. (1). Negative and destructive imagination about potential damages of nanotechnology, whether real or illusionary may result in a threat and slow the growth and development of nanotechnology, unless it is published correctly, in particular information about its dangers and how to prevent them (2). One of the most important of nano-oxides is nano-zinc oxide. These nanoparticles can substitute the macromolecule zinc oxide in various industries and give special properties to the final product (3). Zinc oxide nanoparticles have globular shape and recently, have receivedt more attention in animal studies (4). Production and usage of different synthetic substances have influenced the health of many organisms. The nanoparticles enter in to body through various ways such as skin, inhaling and food (5). Donaldson and coworkers in 2004 made an evolution in toxicology by introducing the science of toxicology

${ }^{1}$ Department of Biology, Payame Noor University, Esfahan, Iran - Employee Social Security Organization, Isfahan, Iran, ${ }^{2}$ Nutrition Research Committee, Faculty of Nutrition, Tabriz University of Medical Sciences, Tabriz, Iran, and ${ }^{3}$ Department of Biology, Faculty of Sciences, Payam Noor University of Isfahan, Isfahan, Iran

Address for correspondence: V. Yousefi Babadi, Department of Biology, Faculty of Sciences, Payam Noor University of Isfahan, Isfahan, Iran, P.O. Box 88611-11111, Isfahan, Iran.

Phone: +98382.7722153, Fax: +98382.7622937 in nanoparticles (6). Despite the widespread uses of nanoparticles, there is limited information about their toxic effects in environment and in humans. Nanoparticles do not have any special problem in passing the physiological barriers due to their small size, so they are widely distributed in the circulation (7-9).

Oxidative stress in biological systems was introduced first by Sies and colleagues. It is an imbalance in oxidant and antioxidant systems in which there is an increase in the oxidant ones that cause damage (10).The production of ROS can disturb mitochondrial function and may also cause changes in the expression of genes that are involved in inflammation and apoptosis.

The science of nanoparticles toxicology will have an important role in the development of stable and safe nanotechnology. Although little information is available about toxic effects of nanoparticles on environment and humans, according to physical-chemical properties of nanoparticles it is expected that these substances interact with biological components and have a large impact on behavior and features of macromolecules, cells and bodies of organisms (11).

In order to study the toxicity of zinc nanoparticles (and other nanoparticles) on different organs a lot of experiments were performed and most of the results are indicating toxicity of them. The largest problem in these studies is the use of high doses in vivo an in vitro researches, although low doses were used in some studies but the number of them is negligible. In the general case the results of many studies indicate toxicity of zinc oxide nanoparticles and its negative effects on the organisms and target cells (12). These nanoparticles can pass from protective layers of body and enter the circulation and cause severe effects $(13,14)$. Recently, it has 
been reported that many concerns exist about the effects of these substance on human health and environment and previous studies have shown that some nanoparticles produce reactive oxygen species (ROS) and free radicals (15) and cause toxicity in laboratory environment (16). An imbalance between antioxidant defense and free radicals production causes a condition that is named oxidative stress and may cause cell damage and it is also very important in pathogenesis of some disease. The outcomes of oxidative stress depending on cell type and severity of oxidative stress are one of the cell proliferation, cell damage, cell death and compatibility or the combination of them (17).

The results of studies show that nano-zinc oxide can have both antioxidant effects $(18,19)$ and be an oxidative stress factor (20-22). It seems this multiple functions are related to the amount of existing material and nanoparticle concentration. Zinc in low doses has beneficial functions in metalloenzymes, transcription factors, immune regulation and growth and synthesis of cell proteins and plays antioxidant, anti-apoptotic and anti-inflammation roles, but in high doses, it has toxic effects and causes oxidative stress through increasing end products of lipid peroxidation and decreasing glutathione and protein thiol levels (23). Cytotoxicity increases with rise in nanoparticles concentration and also exposure time (24). The nanoparticles of zinc oxide can pass from protective layers of body; enter the circulation and lead to severe effects (25) especially predispose individuals to thrombosis in high doses (26). Zinc nanoparticles participate in free radical formation in skin and damage cells and make cause cancer $(27,28)$.Nanoparticles can easily cross from cell membranes and even blood- brain and blood-testis barriers (29, 30, and 31).

Liver is the central organ in metabolism and detoxification. Because of that this organ is the target of different toxins that predispose it to many diseases (32). Sharma and colleagues indicated that zinc oxide nanoparticles could induce oxidative damage in DNA and also cause mitochondrial, genotoxic effects and apoptosis in human liver cells (33). In one study, it has been shown that treatment of mice with nanoscale zinc and microscale zinc components resulted in inflation in the renal glomeruli but there were destructive effects in nano-oxide form and there was no serious damage in testicular tissue observed (34).

\section{Material and methods}

\section{Zinc oxide nanoparticles}

Zinc oxide nanoparticles were prepared from Tecnan, Spain (CAS NO: 1314-13-2, Particle Average Size: 20-30 nm, Specific Surface Area: 35-50 m²/g, Purity: $99.983 \%$ ).

\section{Animals}

It was an experimental study carried out on animals. We used adult male Wistar rats weighing 250-300 g with average age of 2 months. The rats were housed in groups under standard light conditions with free access to water and food. Humidity and temperature $\left(22 \pm 1^{\circ} \mathrm{C}\right)$ were controlled in ventilated cages in a 12-hour day/night cycle. Experimental animals were randomly divided into 6 groups (6 rats in each group). First control group was fed by usual water and food. Second control group that referred to placebo, was injected by $1 \mathrm{ml}$ of distillated water every other day intraperitoneally for equivalency of shock resulting from the intraperitoneal injection. Other groups, 3rd and 4th were injected $1 \mathrm{ml} \mathrm{ZnO-NPs} \mathrm{in} 20$ and $40 \mathrm{mg} / \mathrm{kg}$ doses, injections were repeated every other day intraperitoneally. This continued until 21st day (injection was repeated 10 times). Therefore final dose (20*10 and $40 * 10$ ) was 200 and $400 \mathrm{mg} / \mathrm{kg}$. 5th and 6th group were treated by $1 \mathrm{ml}$ of ZnO-NPs in 200 and $400 \mathrm{mg} / \mathrm{kg}$ doses (single dose) that were considered acute doses. The rats received the same doses in chronic and acute groups. ZnO-NPs resolved in physiological serum in 20 min by sonication method producing a stable suspension. After the mentioned time course blood samples of control and treated rats were prepared and blood levels of hemoglobin, hematocrit, red and white blood cells, lymphocytes, and platelet counts were estimated.

Also, for histological studies liver, kidney and testis were removed and after washing with normal saline for fixation they were placed in Bouin's solution. Then tissue passaging, preparation of paraffin blocks and cutting were performed. Staining was done with hematoxylin-eosin and finally the different cells were examined with an optical microscope.

Data were analyzed using analysis of variance (ANOVA). In the case of a significant ANOVA, post hoc analysis was performed using Tukey's test. Difference level of $\mathrm{p}<0.05$ was considered significant.

\section{Results}

In the present study, we tried to examine the effect of zinc oxide nanoparticles in both acute and chronic doses. For this purposes, two groups of six experimental groups were treated with 200 and $400 \mathrm{mg} / \mathrm{kg} /$ every dose. Two other groups were treated with the same doses but they were divided in 10 doses to increase the exposure of zinc nano-oxide but not to increase the final dose to examine its effects without cumulative rising in nano-oxide concentration in rat to get the aim of this study that was the comparison of chronic exposure against acute exposure.

The study of the effects of different amounts of nano-zinc oxide on WBC and hemoglobin concentrations shows that there were a

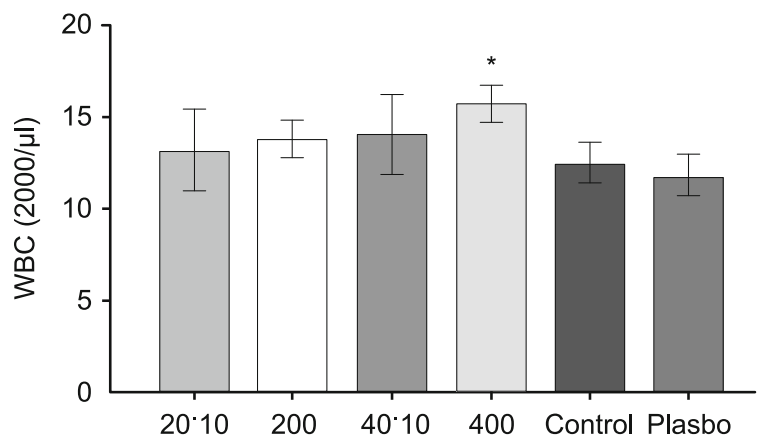

Fig. 1. The effect of zinc nano-oxide on white blood cells. * p value less than 0.05 . 
$616-620$

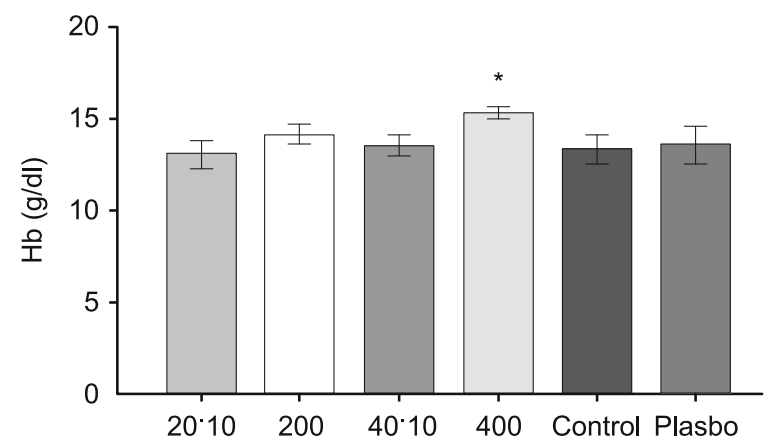

Fig. 2. The effect of zinc nano-oxide on hemoglobin. ${ }^{*} p$ value less than 0.05 .

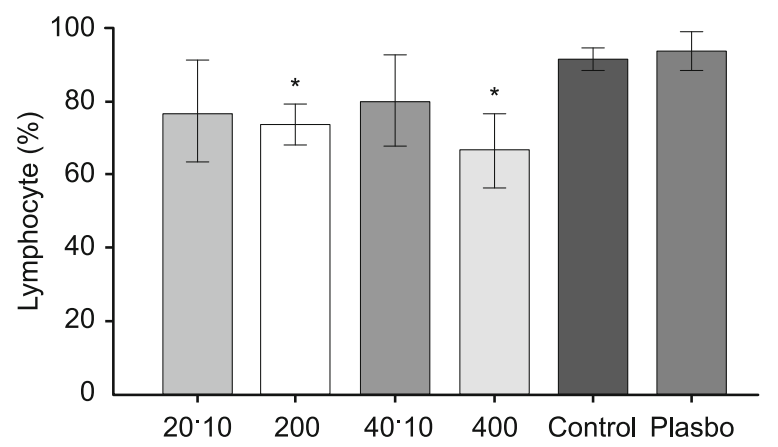

Fig. 3. The effect of zinc nano-oxide on lymphocytes. $*$ p value less than 0.05 .

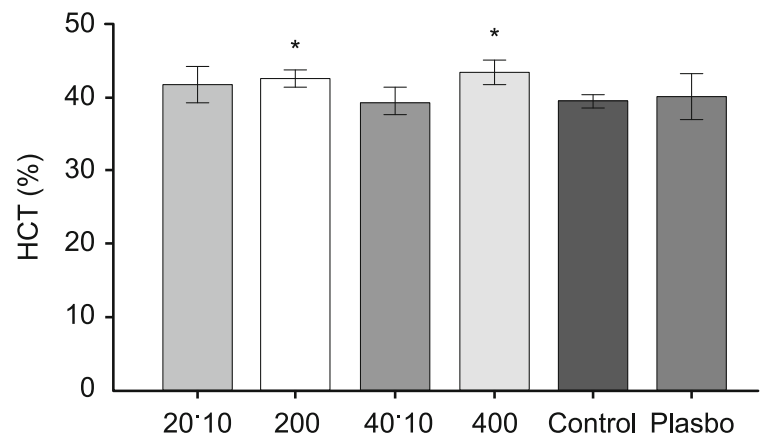

Fig. 4. The effect of zinc nano-oxide on hematocrit. * $p$ value less than 0.05 .

significant differences among groups receiving nano-zinc oxide compared to control group with $400 \mathrm{mg}$ dose but there were no significant differences in other groups including groups receiving $200 \mathrm{mg}$ dose and chronic dose (Figs 1 and 2).

There were significant differences in lymphocytes, hematocrit and platelets in groups receiving nano-zinc oxide (200 and 400 $\mathrm{mg}$ ) compared to control group but no significant change was observed in chronic administrations (Figs 3, 4 and 5). The RBC levels variation between experimental groups and the control group were not statistically significant (data not showed).

The findings in four experimental groups (2 chronic and 2 acute groups) showed that zinc nano-oxide has toxic effect on liver.

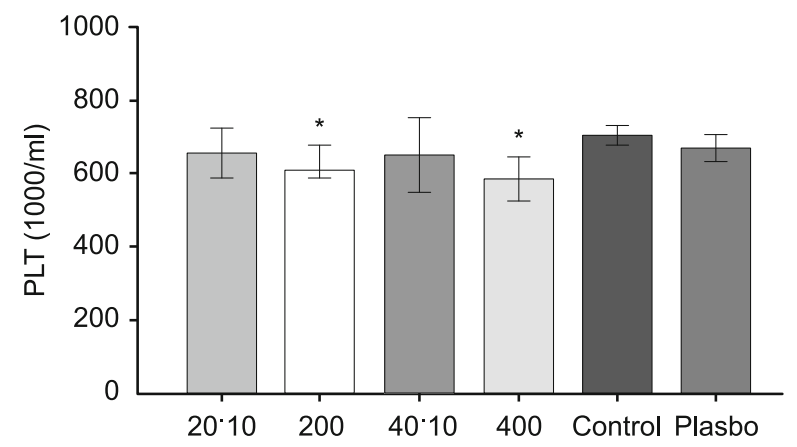

Fig. 5. The effect of zinc nano-oxide on platelets. ${ }^{*}$ p value less than 0.05 .

With the $400 \mathrm{mg} / \mathrm{kg}$ dose, focal hyperplasia of Kupffer cells, mild protitis and small focal collections of lymphocytes were observed in liver parenchyma. There was a lower effects with the $200 \mathrm{mg} /$ $\mathrm{kg}$ dose and in chronic doses including 20 and $40 \mathrm{mg} / \mathrm{kg}$ a few small granulomas in liver parenchyma were observed (Fig. 6).

Histopathological examination of kidney tissue showed some cysts in tubules and slight swellings in glomerulus in acute groups but there were no clear alterations in chronic and control groups (Fig. 7). Also, testicular tissue was normal in all groups and no specific pathological effects were observed (Fig. 8).

\section{Discussion}

In this study, hemoglobin increased with the $400 \mathrm{mg} / \mathrm{kg}$ dose and also hematocrit level elevated in the 200 and $400 \mathrm{mg} / \mathrm{kg}$ dose groups. Whereas these parameters are suggesting an increase in blood concentration, they indicate that nano-zinc oxide has a toxic effect on blood viscosity. It seems that nano-zinc oxide can cause inflammation in inner vessels in acute conditions. One of the most important reasons of increasing blood viscosity is a vascular leak that occurs in inflammatory diseases, infectious diseases and burns. Previous studies also have showed blood leakage from vessel walls with high doses of nano-zinc oxide $(35,36)$. The reason of this can be an increase in expression of VEGF gene that takes place in inflammatory tissues, platelets and immune cells (37-39). Platelets are involved in various aspects of homeostasis. Platelets bind to collagen fibers located beneath the endothelium and prevent bleeding. Reduction in platelet numbers in peripheral circulation results in blood leakage to tissues. Maybe, the effects of oxidative stress on blood platelets and departure of vessels are the other reasons for an increase in hematocrit. Also, white blood cells increased in acute groups. The oxidative stress caused by acute injection of nano-zinc oxide leaded to inflammation in vessels which in turn resulted in WBC accumulation and the release of chemical mediators and further damage to the arteries and spread of inflammation. White blood cells can harm the endothelium by means of releasing cytokines $(40,41)$.

In liver histological examination the effects were severe in acute doses than chronic doses. In 200 and $400 \mathrm{mg} / \mathrm{kg}$ doses focal hyperplasia of Kupffer cells, mild protitis and small focal collections of lymphocytes were obvious. There were a few small granu- 

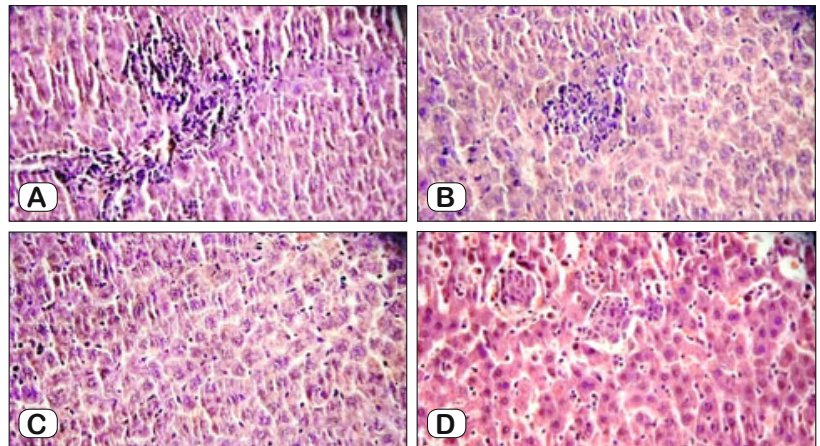

Fig. 6. Photomicrograph of liver tissue: In acute groups were prepared different sections, observations were following: A) mild protitis B) small focal collections of lymphocytes, C) focal hyperplasia of Kupffer cells. In chronic groups, the most obvious finding was D) small granulomas in liver parenchyma.
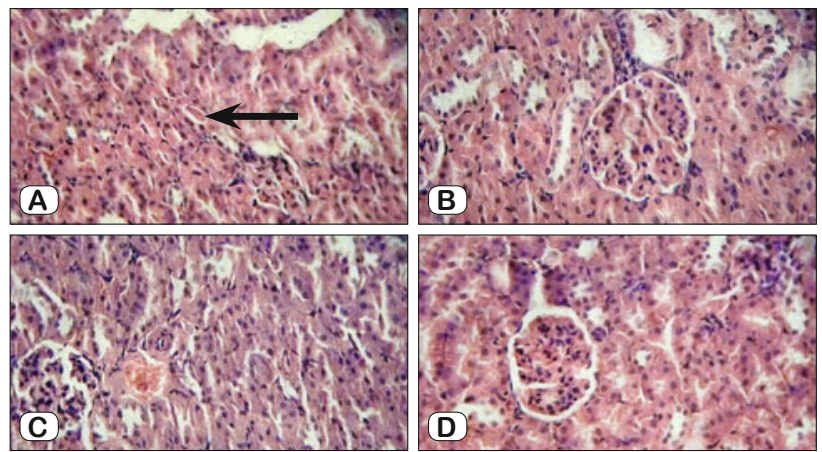

Fig. 7. Photomicrograph of kidney tissue: In acute groups different sections were prepared observations were following: A) cysts in tubules $B$ ) slight swelling in glomerulus $C$ and $D$ ) no clear alterations in chronic groups.

lomas in liver parenchyma in 20 and $40 \mathrm{mg} / \mathrm{kg}$ doses groups. These findings indicate that liver has been exposed to chronic inflammation that it is consistent to some extent with Cho and coworkers study about nano-zinc oxide effect and granulomatous in liver (42). Kupffer cells have critical role in deleting nanomaterials, so liver tissue is more vulnerable than other organs (43). Considering the measure of liver damage in acute dose to chronic dose in addition to nano-zinc oxide dose, can point to liver tissue tolerance and rapid elimination from blood by other systems such as lymph nodes and spleen-reticular-endothelial system in chronic groups compared to acute groups.

We observed some renal tubular cysts and slight swelling in renal glomerulus with acute doses but there was no clear alteration in renal glomerulus with chronic doses. These differences may relate to acute dose of nano-zinc oxide like liver. On the other hand, based on previous studies reticular-endothelial systems of liver and spleen and lymph nodes have essential role in elimination of nanomaterials from circulation. So it is conceivable that there is less damage in kidney than liver that is consistent with our findings. As inflammation can lead to oxidative stress and vice versa, so it can be concluded that oxidative stress caused by nano-zinc oxide is the main factor in inflammatory effects of this substance on liver and kidney.
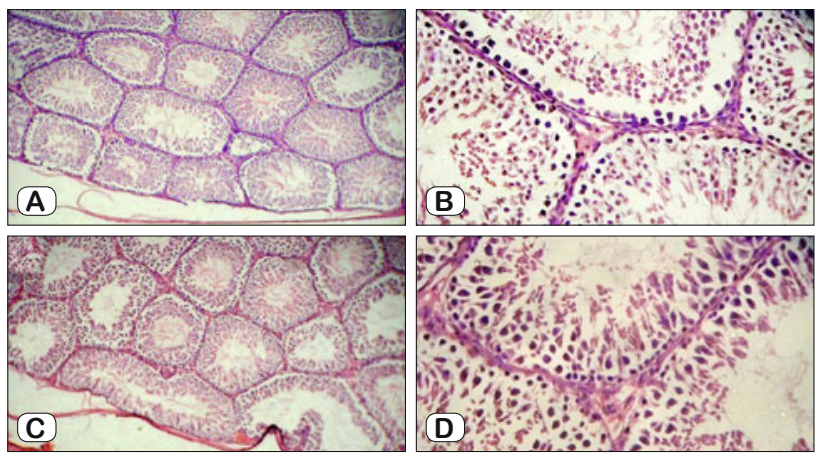

Fig. 8. Photomicrograph of kidney testicular tissue: without clear pathologic finding in A and B) acute groups and $C$ and D) chronic groups.

Finally, no damage was seen in testicular tissue that is probably due to insufficient concentration of nano-zinc oxide for effecting testis. This finding is consistent with Bing Wang`study that has shown that certain concentrations of nano-zinc oxide have toxic effects on the kidney, but same concentration did not cause visible effects on testicular tissue (34).

\section{Conclusion}

Nano-zinc oxide has different effects on one organ in different concentrations and different time exposure. Also, all organs are not destroyed at the same measure and a concentration that is toxic for on organ is not probably toxic for other organs. Finally, it seems that exposure to a high concentration of zinc nano-oxide compared to same concentration but in divided doses and longer time has more destructive effects on body tissues.

\section{References}

1. Hernandezbattez A, Gonzalez R, Viesca J, Fernandez J, Diazfernandez $\mathbf{J}$, Machado $\mathrm{A}$. $\mathrm{CuO}, \mathrm{ZnO}_{2}$ and $\mathrm{ZnO}$ nanoparticles as antiwear additive in oil lubricants. Wear 2008; 265: 422-428.

2. Maynard AD. Nanotechnology: A Research Strategy for Addressing Risk (Woodrow Wilson International Center for Scholars, Washington DC, 2006).

3. Heinlaan M, Ivask A, Blinova I, Dubourguier HC, Kahru A. Toxicity of nanosized and bulk $\mathrm{ZnO}, \mathrm{CuO}$ and $\mathrm{TiO}_{2}$ to bacteria Vibrio fischeri and crustaceans Daphnia magna and Thamnocephalus platyurus. Chemosphere 2008; 71 (7): 1308-1316.

4. Dawei A, Zhisheng W, Anguo Z. Protective Effects of Nano-ZnO on the Primary Culture Mice Intestinal Epithelial Cells in in vitro Against Oxidative Injury. World J Agri Sci 2010; 6 (2): 149-153.

5. Lin D, Xing B. Phytotoxicity of nanoparticles: inhibition of seed germination and root growth. Environ Pollut 2007; 150: 243-250.

6. Donalson K. Nanotoxicology. Occup Environ Med 2004; 61: 727-728.

7. Cristina B, Ivan I, Pache CO, Robbie K. Nanomaterials and nanoparticles: sources and toxicity. Biointer Phases 2007; 2 (4).

8. Elder A, Gelein R, Silva V, Feikert T, Opana Shukl, Carter J, Potter R, Maynard A, Ito, Finkelstein J, Oberdorster G. Translocation of 


\section{$616-620$}

inhaled ultrafine manganese oxide nanoparticles to the central nervous system. Environ Health Perspect 2006; 114: 1172-1178.

9. Oravecz K, Kalka D, Jeney F, Cantz M, Nagy IZ. Hydroxyl free radicals induce cell differentiation in SK-N-MC neuroblastoma cells. Tissue Cell 2002; 34 (1): 33-38.

10. Abdollahi M, Ranjbar A, Shadnia SH, Nikfar SH, Rezaie A. Pesticides and oxidative stress: A review. Med Sc Monit 2004; 10 (6): 141-147.

11. Revell PA. The biological effects of nanoparticles. Nanothechnol Percept 2006; 2: 283-298.

12. Jones N, Ray B, Ranjit KT, Manna AC. Antibacterial activity of ZnO nanoparticle suspensions on a broad spectrum of microorganisms. FEMS Microbiol Lett 2008; 279 (1): 71-76.

13. Lockman PR, Oyewumi MO, Koziara JM, Roder KE, Mumper RJ, Allen DD. Brain uptake of thiamine-coated nanoparticles. J Control Release 2003; 93 (3): 271-282.

14. Barbu E, Molnar E, Tsibouklis J, Gorecki DC. The potential for nanoparticle-based drug delivery to the brain: overcoming the blood-brain barrier. Expert Opin Drug Deliv 2009; 6 (6): 553-565.

15. Yoshida Y, Ltoh N, Satio Y, Hayakava M, Niki. Application of water soluble radical initiator,2,2-asobis [2-(2-1-midazolin-2-yi)propane]dihydro chloride to study of oxidative stress. Free Radic Res 2004; 38: 375-384.

16. Brandt D, Park B, Hoang M, Jacobe HT. Argyria: secondary to ingestion of homemade silver solution. J Am Acad Dermotal 2005; 53 : S105-S107.

17. Malekirad AA, Ranjbar A, Rahzani K, KadKhodaee M, Rezaie A, Thaghavi B, Abdollahi M. Oxidative stress in operating room personnel: occupational exposure to anesthetic gases. Human Experiment Toxicol 2005; 24 (11): 597-601.

18. Dawei A, Zhisheng W, Anguo Z. Protective Effects of Nano-ZnO on the Primary Culture Mice Intestinal Epithelial Cells in in vitro Against Oxidative Injury. World J Agri Sci 2010; 6 (2): 149-153.

19. Lina T, Fenghua Z, Huiying R, Jianyang J, Wenli L. Effects of Nano-zinc Oxide on Antioxidant Function in Broilers. China J AN 2009; 21: 534-539.

20. Heng BC. Toxicity of zinc oxide $(\mathrm{ZnO})$ nanoparticles on human bronchial epithelial cells (BEAS-2B) is accentuated by oxidative stress. Food ChemToxicol 2010; 48 (6): 1762-1766.

21. Moos PJ. ZnO particulate matter requires cell contact for toxicity in human colon cancer cells. Chem Res Toxicol 2010; 23 (4): 733-739.

22. De Berardis B et al. Exposure to $\mathrm{ZnO}$ nanoparticles induces oxidative stress and cytotoxicity in human colon carcinoma cells. Toxicol Appl Pharmacol 2010. In press.

23. Kasperczyk S, Przywara-Cchawaniec B, Kasperczy KA, Rykaczewska-Czerwinska M, Wodniecki J, Birkner E. Function of heart muscle in people chronically exposed to lead. Ann Agric Environ Med 2005; 12: 207-210.

24. Sharma V, Shukla RK, Saxena N, Parmar D, Das M, Dhawan A. DNA damaging potential of zinc oxide nanoparticles in human epidermal cells. Toxicol Lett 2009; 185: 211-218.

25. Jones N, Ray B, Ranjit KT, Manna AC. Antibacterial activity of ZnO nanoparticle suspensions on a broad spectrum of microorganisms. FEMS MicrobiolLett 2008; 279 (1): 71-76.

26. Hughes S, Samman S. The effect of zinc supplementation in humans on plasma lipids, antioxidant status and thromgbogenesis. J Am Coll Nutr 2006; 25: 285-291.
27. Bystrzejewska-Piotrowska G, Golimowski J, Urban PL. Nanoparticles: their potential toxicity, waste and environmental management. Waste Manag 2009; 29 (9): 2587-2595.

28. Gurr JR, Wang ASS, Chen CH, Jan KY. Ultrafine titanium dioxide particles in the absence of photoactivation can induce oxidative damage to human bronchial epithelial cells. Toxicol 2005; 213 (1-2): 66-73.

29. McAuliffe ME, Perry MG. Are nanoparticles potential male reproductive toxicant? A literature review. Nanotoxicol 2007; 1: 204-210.

30. Bystrzejewska-Piotrowska G, Golimowski J, Urban PL. Nanoparticles: Their potential toxicity, waste andenvironmental management. Waste Management 2009; 29 (9): 2587-2595.

31. Barbu E, Moln RV, Tsibouklis J, Grecki DC. The potential for nanoparticle-based drug delivery to the brain: overcoming the blood-brain barrier. Expert Opinion on Drug Delivery 2009; 6 (6): 553-565.

32. Meyer SA, Kulkarni AP. Hepatotoxicity. In: Hodgson E, Smart RC (Eds). Introduction to biochemical toxicology. New York: A. John Wiley \& Sons, Inc., 4, 2001, 487-490.

33. Sharma V, Anderson D, Dhawan A. Zinc oxide nanoparticles induce oxidative DNA damage and ROS-triggered mitochondria mediated apoptosis in human liver cells (HepG2). Apoptosis 2012; 17: 852-870.

34. Bing Wang, Wei-YueFeng, Tian-Cheng Wang, Guang Jia, Meng Wang, Jun-Wen Shi, Fang Zhang, Yu-Liang Zhao, Zhi-Fang Chai. Acute toxicity of nano- and micro-scale zinc powder in healthy adult mice. Toxicol Lett 2006; 161: 115-123.

35. Lingen MW. Role of leukocytes and endothelial cells in the development of angiogenesis in inflammation and wound healing. Arch Pathol Lab Med 2001; 125: 67-71.

36. Sano H, Hosokawa K, Kidoya H, Takakura N. Negative regulation of VEGF-induced vascular leakage by blockade of angiotensin II type 1 receptor. Arterioscler Thromb Vasc Biol 2006; 26 (12): 2673-2680.

37. Mechtcheriakova D, Schabbauer G, Lucerna M, Clauss M, De Martin R, Binder BR, Hofer E. Specificity, diversity, and convergence in VEGF and TNF-alpha signaling events leading to tissue factor up-regulation via EGR-1 in endothelial cells. FASEB J 2001; 15 (1): 230-242.

38. Tonnesen MG, Feng X, Clark RA. Angiogenesis in wound healing. J Invest Dermatol Symp Proc 2000: 5: 40-46.

39. Verheul HM, Jorna AS, Hoekman K, Broxterman HJ, Gebbink MF, Pinedo HM. Vascular endothelial growth factor-stimulated endothelial cells promote adhesion and activation of platelets. Blood 2000; 96: 4216-4221.

40. Mills J, Mansfield M, Grant P. Elevated fibrinogen in the healthy male relatives of patients with severe, premature coronary artery disease. Eur Heart J 2002; 23 (16): 1276-1281.

41. Bradran A, Nasri H. Association between white blood cell count and levels of serum homocysteine in end-stage renal failure patients treating with hemodialysis. J Ayub Med Coll Abbottabad 2006; 18 (1): 22-26.

42. Cho WS, Duffin R, Poland CA. Metal oxide nanoparticles induce unique inflammatory footprints in the lung: important implications for nanoparticle testing. Environ Health Perspect 2010; 118 (12): 1699-1706.

43. Sadauskas E, Wallin H, Stoltenberg M. Kupffer cells are central in the removal of nanoparticles from the organism. Particle FibreToxicol 2007; 4: 10

Received September 14, 2014. Accepted October 1, 2014. 